\title{
Analysis and Prevention of Major Coal and Gas Outburst Accident
}

\author{
Dai Linchao ${ }^{1,2, \text { a * }}$ \\ ${ }^{1}$ Gas Research Branch, China Coal Technology Engineering Group Chongqing Research Institute, \\ Chongqing 400037, China \\ ${ }^{2}$ State Key Laboratory of the Gas Disaster Detecting Preventing and Emergency Controlling, \\ Chongqing 400037, China \\ adailinchao@126.com
}

\begin{abstract}
Malignant coal and gas outbursts have occurred frequently, and it will cause a lot of casualties, enormous property losses and adverse social influence. Aiming at the Guizhou Xinhua coal mine 6.11 major coal and gas outburst accident, the main causes of the accidents were analyzed, the lessons learned from accidents were summarized, and the corresponding accident preventive measures were put forward and implemented to ensure the daily safety and efficient production of coal mine.
\end{abstract}

Keywords: Coal mine, coal and gas outburst, major accident, preventive measures

\section{Introduction}

Xinhua coal mine is located in the Liuzhi special economic zone of Guizhou and is $30 \mathrm{~km}$ away from the urban area of Liuzhi District, belonging to Guizhou Hualong Coal Industry Co., Ltd. The Xinhua coal mine started construction in September 2009, and has an area of $51.3 \mathrm{~km}^{2}$, recoverable reserves of 86.26 million tons, and a designed production capacity of 1.2 million tons per year. The mine was developed using flat boring and divided into two levels of $+1350 \mathrm{~m}$ and $+1050 \mathrm{~m}$. There are 13 panels and 7 mining areas, which are divided into upper, middle and lower coal groups for mining[1]. The first working face is designed to be a 1601 working face in a panel on the horizontal coal group, adopting the inclined longwall mining method and adopting the comprehensive mining technology. The gas content of the M6 coal seam in the area above the +1340 level is 12.49 to $18.38 \mathrm{~m}^{3} / \mathrm{t}$, the original gas pressure is 0.13 to $1.65 \mathrm{MPa}$, and the $\mathrm{M} 6$ coal seam above the +1340 level has the danger of coal and gas outburst. The mine is the outstanding mine. The first mining face gas treatment, the use of floor extraction tunnel pre-plumbing coal roadway and the recovery area gas, gas extraction M6 coal seam from the normal distance of $20 \mathrm{~m}$.

\section{Summary of the outburst accident}

A coal and gas outburst accident occurred at the coal exposing face of the No.2 liaison road of Xinhua Coal Mine's 1601 return air trough at 0:07 on June 11th, 2014. Highlighting the length of the coal-mesh stacking wells is $139 \mathrm{~m}$, the amount of outburst coal is 1010 tons, the amount of outburst gas is about $120,000 \mathrm{~m}^{3}$, and the accident results in 10 deaths. The accident belongs to the major coal and gas outburst, and the design length of the No.2 connecting lane of the 1601 air returning trough of the accident site is $43 \mathrm{~m}$, and the opening point is located at 101 methane drainage lane $\mathrm{K} 0+1250 \mathrm{~m}$, the slope is $+25^{\circ} 30^{\prime}$, and the azimuth angle is $220^{\circ}$. The angle of orientation with the 1601 return air slot is $20^{\circ}$. The roadway has been excavated for $35 \mathrm{~m}$. The coal seam has been removed from the coal seam floor on June 5th. It is now in the coal stage of the M6 coal seam. The coal gate is $7.5 \mathrm{~m}$ long and has passed the coal gate for $2.5 \mathrm{~m}$. The coal seam has been exposed to the top of the working face facing the top $1.4 \mathrm{~m}$. The Lane is used for 1601 return air along the tunnel to dig in and transport. 


\section{Cause Analysis of the outburst accident}

Guizhou Xinhua coal mine 1601 return air trough 2\# roadway uncovered in the demolition coal area failed to meet the standard, and it did not eliminate the outstanding dangers. Coal and gas outbursts were induced by the coal gate firing. Through the analysis of the accident, it was found that the main reasons are as follows.

(1) The implementation of regional outreach measures is not in place. The coal seam thickness in this area is 4.5 meters and is soft. When the drainage holes are drilled in the area, the borehole is easy to be bored in the deep part of the coal seam. In addition, because a small number of boreholes are too soft, the borehole does not penetrate the full thickness of the coal seam during the drilling, leading to the coal seam section in front of the uncovered coal. The coal has not been effectively evacuated and the coal exposing area has not fully met the standard. Therefore, the coal seam has been prominently exposed after the coal seam has been safely uncovered. Although gas fracturing technology has been used, the elimination effect has not yet been achieved.

(2) Gas drainage volume measurement statistics have error. According to the relevant information on the mine, 88 floors with gas drainage in the coal seam of the coal-exposed area were drilled for a total of $24,000 \mathrm{~m}^{3}$ for more than 14 months, while the 99 holes drilled on the coal exploding face measured the total amount of drainage reached $113,000 \mathrm{~m}^{3}$ in about 1 month, and there are errors.

(3) Regional measures effect inspection samples are not operated properly. When directly measuring the gas content of coal seams, the boreholes drilled into the 1 to $2 \mathrm{~m}$ section of drill cuttings were used as coal samples. Cores were not cored according to the procedure. The measured data could not truly reflect coal seam gas parameters.

(4) Measures effect test sensitivity indicators are inappropriate choice. After the coal roadway was opened and the coal continued to be excavated, the determination reached $0.79 \mathrm{ml} / \mathrm{g} \cdot \mathrm{min}^{1 / 2}$, which exceeded the critical value of the outburst danger. The initial velocity of drilling gas and the other auxiliary indicators were used as the measure effect indicators test. If the index does not exceed the regulation, the construction is organized. The sensitive indicators were selected so as to fail to accurately detect the outstanding dangers existing in the working face.

(5) Anti-burst door construction does not meet the requirements. The anti-burst door is located at a distance of 160 meters from the 160th air return gate along the trough $2 \#$. There are only two reverse dampers, the damper building quality is poor, the damper wall is not thick enough, and the wall is hollow, meanwhile the damper wall is surrounded by no guttering. This operation violates the article 103 relevant regulations of the literature[2]. After the outburst occurred, the facilities were destroyed, the winds reversed, and the accident expanded.

(6) Placing shots to evacuate people are not in place. According to the provisions of the coal exposing measures in No.2 of the 1601 return air trough, all underground personnel must be evacuated to the ground when blasting. In addition, the above-mentioned regulations were not strictly enforced on duty, and the rescue team was not notified to stand by on the spot, resulting in the death of those who did not withdraw.

\section{Lessons learned of the outburst accident}

Through the analysis of the outstanding accidents mentioned above, the following lessons have been learned.

(1) The implementation of regional outburst prevention measures, the effectiveness of regional measures, verification, and the prediction and inspection of local outbreak prevention measures must be rigorously controlled and validated to ensure the prevention and control of the outburst prevention process and up to standard. The quality, effectiveness and responsibilities of the outbreak prevention project were implemented in district teams, teams and individuals.

(2) The indicators for gas control and prevention must be authentic and reliable. The inspection of the effectiveness of the measures must be carried out in strict accordance with the procedures to ensure that the coal seam methane residue indicators measured are true and reliable. And the installation of gas 
in accordance with the standard shall be carried out on the line monitoring metering device, and accurate drainage measurements shall be made to provide accurate basis for the evaluation of the outburst prevention appraisal and the appraisal of the standard for extraction.

(3) New mine gas management should be based on geological data. Seriously analyze and study the natural properties of the first coal seam, such as permeability, sturdiness, and gas occurrence patterns, and adopt effective targeted measures for governance. For example, the mine M6 coal seam gas management should be based on the thick, soft, low permeability characteristics of the coal seam to study and solve the technical problems of easy boring and difficult drainage. At the same time, according to the principles of safety, reliability, and effectiveness, the sensitive indicators and critical values of the outburst risk prediction are studied and established, and prominent risk prediction techniques that are mainly sensitive indicators and other auxiliary judgment indexes are established.

(4) Strengthen outburst prevention management. Conscientiously implement the requirements of the regulations[2,3], establish a technology system for preventing outbursts, set up outreach agencies as required, perform the separation of the three rights of construction, inspection and acceptance, and evaluation of drilling, and improve the management system and post responsibility system for prevention of outbursts and strictly enforce them. In particular, it is necessary to establish a management system and a reward and punishment system for the effective implementation of safety engineering quality, and to strengthen the quality control of gas drainage projects.

(5) Strict implementation of security measures. Outbreak prevention facilities must be strictly constructed in accordance with the provisions of the article 103 relevant regulations of the literature[2] to ensure that the position and quality of the anti-spill doors are in compliance with the outburst prevention requirements. The whole process of uncovering coal in Shimen must be evacuated and guarded in strict accordance with the provisions of measures, and safety protection measures for long-range blasting should be implemented to prevent accidents from expanding.

(6) Strengthen the training of coal mine workers' safety knowledge and improve their independent security awareness and self-rescue capability. While establishing and improving the underground safety facilities, disaster escape exercises are conducted in a timely manner so that workers can master the skills of using wells and downhole safety facilities at critical moments, and play the role of safety facilities.

\section{Preventive measures to implement}

At present, all the mines of the group companies are shut down for production and shutdown for safety special rectification, and implementation of comprehensive preventive measures is implemented in 7 aspects including safety ideology, safety responsibility, management system, institution construction, staff training, mine systems, safety investment, and occupation access to avoid highlighting accidents.

(1) Safety ideological reorganization activities throughout the company are carried out. In accordance with the Circular of the Safety Supervision Office (2014) No. 24 "Continuing the Notice on Further Strengthening the Province's Production Shutdown (Construction) to Reorganize Coal Mine Safety", the company carry out the "safety reorganization, hidden danger elimination, and basic foundation" safety Remediation activities. Seriously learn lessons from accidents, and fully establish the first thought of safety. We must respect life, fear the system, and respect job responsibilities, and correctly handle the relationship between safety and production, and safety and development.

(2) Establish and improve the responsibility system for safety production and achieve the strictest safety production system. Responsibility is the soul of safety production, and the responsibility system cannot be strictly enforced. Failure to implement it is the main contradiction in safety production. Through the establishment of a sound responsibility system for safety production, the dereliction of duty by management cadres and posts at all levels is eliminated, and the blind spot of liability is strictly eliminated. Safety production laws and regulations and rules and regulations, intensify inspection efforts, and implement the most stringent safety production system in terms of safety management, 
responsibility implementation, technical management, hidden trouble investigation, and strictly control the risk of system failure.

(3) Further strengthen technical management. Establish a technical management system headed by the chief engineer, optimize mining and deployment, rationally arrange production, and prepare a plan for the prevention of outbursts while preparing the production plan so that the excavation and mining balance can be achieved. Strictly review and approve the design of technical solutions and preparation of measures, and do a good job in construction technology management. Strengthen the management of safety production systems, build a gas management system, ensure reliable ventilation, effective monitoring, compliance with standards, and management.Promote the use of new technologies, new processes, new materials, and actively explore new technologies for low gas permeability and soft coal seam gas treatment.And rely on advances in science and technology to improve the safety production capacity.

(4) Effectively strengthen the prevention and control of coal and gas outbursts. Strict implementation of the two "four-in-one" comprehensive anti-riot measures[4,5]. Take effective measures to supervise and effectively verify the gas control project, resolutely eliminate falsification in gas control work, eliminate spurious drilling, false prevention, and false elimination, and unequivocally question the lack of process monitoring and control projects, or push it back again.Resolutely do not dig out the head, not to use prominent face. The group company and its principal responsible persons and technical persons in charge regularly visit the site to inspect the implementation of the implementation measures and solve the problems found in a timely manner.

(5) Strengthen the management of key work, key parts, and key links in coal mines.Conscientiously carry out the Guizhou Province Coal Mine Safety Supervision Bureau's activities to develop coal mines' "inspection system, eliminate hidden hazards, and prevent major accidents", and investigated system defects from seven aspects such as "opening up the system and extracting and deploying" to eliminate major hidden dangers and prevent the occurrence of the major accidents.

(6) Strengthen the construction and management of the outbreak prevention facilities.Strict anti-explosive facility design, construction, and acceptance management. Outbreak prevention facilities must be strictly constructed in accordance with the provisions of the article 103 relevant regulations of the literature[2] to ensure that the position and quality of the anti-spill doors are in compliance with the requirements for preventing outbursts and improve the ability of mines to resist disasters.

(7) Strengthen the safety management of the external construction team.The infrastructure mine is the main responsibility for safety construction. It is necessary to strengthen the safety management of the construction project of the external committee, strictly perform the duties of the "safety production law" on the safety management regulations of the contracted project, and it is forbidden to appear to entrust the excavation with the package management.

\section{Conclusion}

This article focuses on the major coal and gas outburst accidents in Xinhua Coal Mine in June 2014. It is considered that the failure of the 1601 air return along trough No.2 in the uncovered area of coal roads is the root cause of major outbreaks, and summarizes the experience and lessons learned from accidents. And we should implement preventive measures for outstanding disasters in terms of safety ideology, safety responsibilities, management systems, institution building, staff training, mine systems, safety inputs, and occupational access. Only with the actual situation of on-site production of coal mines and the development of targeted preventive measures for outstanding disasters, can we achieve the goal of realizing the daily safe and efficient production of coal mines, and eliminate the occurrence of coal and gas outburst accidents. 


\section{Acknowledgments}

This study was financially supported by National Natural Science Foundation of China (51574280, 51604298, 51774319), The Science and Technology Innovation Fund of China Coal Technology \& Engineering Group (2015ZDXM14).

\section{References}

[1] Y.Q. Yuan, S.Z. Zhang, Characteristics of coal measures and coal quality of upper permian in Guizhou Liuzhi Xinhua coal mining area, Guizhou Geology, 2(2007)110-113.

[2] State Administration of Work Safety Supervision and Administration, National Coal Mine Safety Supervision Bureau, Prevention of coal and gas outburst regulations, Coal Industry Press, Beijing, 2009.

[3] National Coal Mine Safety Supervision Bureau, Coal mine safety regulations, China Legal Publishing House Publishing, Beijing,2016.

[4] Y.Z. Zhang, W.F. Wang, J.Q. Hou, Outlining the four-in-one comprehensive anti-outburst measures for coal seam excavation face, Coal Technology,3(2007)58-60.

[5] C.G. Wang, Application and evaluation of quaternity outburst prevention system in lower working face containing coal pillar, Safety in Coal Mines,10(2016)126-129. 